\title{
A Fuzzy Logic Controller Based on Maximum Power Point Tracking Algorithm for Partially Shaded PV Array-Experimental Validation
}

\author{
Boualam Benlahbib ${ }^{1,2,3}$, Noureddine Bouarroudj ${ }^{1}$, Saad Mekhilef ${ }^{3}$, Tameur Abdelkrim¹, \\ Abdelkader Lakhdari ${ }^{1}$, Farid Bouchafaa ${ }^{2}$ \\ ${ }^{1}$ Unite de Recherche Appliquee en Energies Renouvelables (URAER), \\ Centre de Developpement des Energies Renouvelables (CDER), \\ 47133 Ghardaia, Algeria \\ ${ }^{2}$ Laboratoire d'Instrumentation, Faculte d'Electronique et d'Informatique (USTHB), \\ 16111 Alger, Algeria \\ ${ }^{3}$ Power Electronics and Renewable Energy Research Laboratory (PEARL), \\ Department of Electrical Engineering, University of Malaya, \\ 50603 Kuala Lumpur, Malaysia \\ bouallam30@gmail.com
}

\begin{abstract}
In the last two decades, the maximum power point tracking (MPPT) methods for PV system is becoming very interesting subject. Among these methods there is FuzzyMPPT, which is mainly based on two inputs and at least 25 rules. This structure need more calculation time and not easy to be implemented in hardware. For these reasons and in order to facilitate the MPPT synthesis, this paper proposes an intelligent MPPT controller based on a single-input Takagi-Sugeno fuzzy logic controller (SI-TS-FLC) with three linguistic variables and three rules. The proposed controller is simulated using MATLAB-SIMULINK for a PV system, which consists of a PV generator, DC-DC converter, and resistive load under varied temperature and irradiance levels. An experimental study is conducted using DSPACE 1104 card real-time board under partial shading condition. Simulation and experimental results show that the proposed controller exhibits less settling time and lower overshoot than the commonly used perturb and observe (P\&O) algorithm in the transient state and minimum oscillation around the optimal operating point.
\end{abstract}

Index Terms-Fuzzy control; Maximum power point trackers; Photovoltaic systems; Takagi-Sugeno model.

\section{INTRODUCTION}

Currently, environment pollution issues, particularly climate change, cannot be neglected. According to many scientists, climate change is mainly due to the disastrous effects of emissions of greenhouse gases, particularly $\mathrm{CO}_{2}$, which are responsible for global warming and increase in the earth's temperature. Global warming causes several natural cataclysms, such as floods, cyclones, soil erosion, and losses in genetic diversity, in several locations worldwide. These natural disasters present an unprecedented ecological threat

Manuscript received 17 October, 2017; accepted 24 May, 2018.

This research was financially supported by the Directorate General for Scientific research and Technologies Development- Algerian Ministry of Higher Education and Scientific Research. on the ecosystem equilibrium; such as, scholars must device an urgent plan to shift to renewable energy resources. The following questions arise among the members of the scientific community: Which type of renewable energy resource is suitable for height conversion rate? How do we efficiently control the energy collected from renewable resources?

Solar energy, following wind energy, is one of the most exploited renewable energy resources. According to the Renewable Global Status report 2016 (REN21), the solar PV market reached $25 \%$ in 2014 to a record of $50 \mathrm{GW}$, increasing the total global value to $227 \mathrm{GW}$. The annual market for solar PV market in 2015 is approximately 10 times higher than the global cumulative solar PV capacity a decade earlier. China, Japan, and the United States account for most of the capacity added. Other emerging markets in different regions have contributed significantly to global growth due to improvements in the cost-competitiveness of solar PV [1].

Solar PV technology is one of different technologies with great potential for development due to its simplicity of use, but the major problem of this energy source is the low efficiency of energy conversion. In this regard, the MPPT controllers are used and have become a key element in these systems. Several methods have been developed to determine MPPT; such methods include the commonly used perturb and observe (P\&O) algorithms [2] based on the PV voltage or current variations to detect the PV output power. The $\mathrm{P} \& \mathrm{O}$ algorithm with modified structure has also been proposed to avoid the problems of power loss and system instability around the optimal operating point [3]. In [4] and [5], authors have developed the increment conductance method to eliminate oscillations around the MPP. Another MPPT controller was developed using short-current pulse of the PV [6]. However, these conventional methods generally 
fail to track the MPP if parts of the PV cells are partially shaded or damaged.

Artificial intelligence methods have been used to design MPPT controllers; such methods include artificial neural networks [7]-[9], particle swarm optimization (PSO) method [10], [11], fireworks-enriched algorithm (FE) [12], [13], and fuzzy logic controller (FLC)-based Mamdani or T-S model [14]-[16]. The FLC has been introduced to overcome the limitations of $\mathrm{P} \& \mathrm{O}$ or hill-climbing algorithm [17]. As reported in [18], the FLC can be combined with hillclimbing (HC) technique to avoid the drawback of conventional HC. The FLC is designed by translating the $\mathrm{HC}$ algorithm into 16 fuzzy rules. However, steady-state error occurs in the PV output power. To eliminate oscillation around MPP, authors in [17] proposed an MPPT control algorithm based on FLC technique with two inputs and 49 membership function rules. Results show that the calculation algorithm time is significant. To further improve the performance of conventional MPPT methods, authors in [19] combined the robustness of the FLC with the accuracy of fractional-order technique. The proposed method exhibits excellent performance in terms of short settling time and low steady-state error. Although the method proposed in [19] has improved the settling time and steady-state error, real-time implementation of this method is approximately complex and requires expensive microcontrollers. In addition, the method uses 2 inputs and 25 membership function rules to design FLC and thus requires a high computation time. In [20], a new approach was developed based on a single-input FLC for MPPT to reduce the controller complexity; the input of the fuzzy controller is the signed perpendicular distance ds calculated from error (E) and the change of error (CE) of conventional FLC. This algorithm uses more than three normalized membership function rules.

Most studies on FLCs use two inputs [21], [22]: the first input is for calculating the error $(E)$ from the change of power $\Delta \mathrm{P}$ divided by the change of voltage $\Delta \mathrm{V}$; the second input is the error variation $(C E)$ for determining the operating point location, regardless of the right or left half plan. Based on the variations in $E$ and $C E$, the duty-ratio output will be changed to reach the MPP. The design of the FLC complicates the determination of its corresponding parameters. As such, scholars introduced genetic algorithm (GA) [15], [23] and PSO algorithm [24]-[26] to compute the optimal parameters of membership functions.

Based on the gap in literature, this study proposes a T-S FLC with a single input (SI TS-FLC), where error E is the single input. In this approach, the number of membership functions and rules is reduced compared with fuzzy logic with two inputs. To optimize controller parameters, we used PSO algorithm to minimize the cost function of the integral time multiplied by absolute error (ITAE) [27], [28].

The proposed approach is validated by simulation under various conditions of temperature and irradiance and through experiment under partial shading condition.

\section{Photovoltaic System AND MPPT CONTROLleR}

The use of PV system shown in Fig. 1 is made up of a PV generator, a resistive load, and a DC-DC boost converter; which is a power electronic device used to increase the input DC voltage; controlled by the MPPT algorithm.

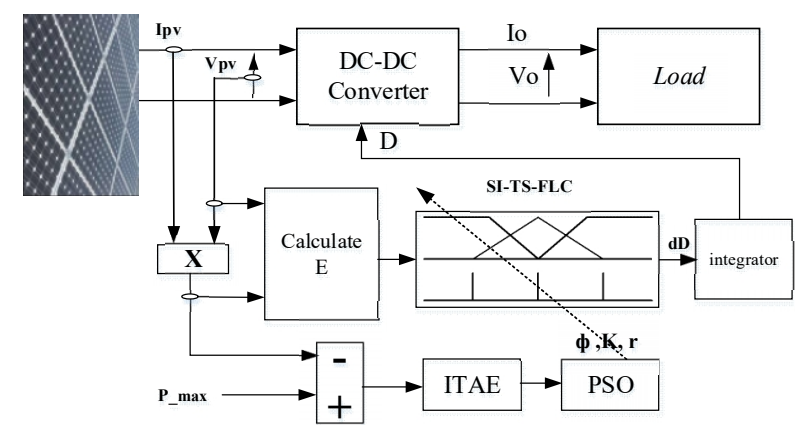

Fig. 1. Block diagram of a photovoltaic system.

MPPT controllers are commonly used to achieve optimal operation of the PV system. The principle of this control strategy is based on automatically varying the duty cycle $D$ in order to obtain the optimum value related to maximize the power delivered by the PVG. For this reason, we will subsequently study the most commonly used control algorithms, such as $\mathrm{P} \& \mathrm{O}$ algorithm and introduce a novel technique based on an SI-TS-FLC.

\section{A. Proposed Fuzzy Logic Controller Based on a Single Input}

FLC was introduced by some researchers to design an MPPT controller for renewable energy resources - [16], [19], [21]. Results obtained through the applications of this controller show superior robustness and tracking precision compared with the conventional algorithm P\&O. TakagiSugeno's fuzzy controllers can approximate any nonlinear behavior according to results adopted in designing controllers for nonlinear systems [22], [23].

First, the reason of choosing single input to the FLC has been clarified by employing the P-V curve of the PV system.

From the flow chart shown in Fig. 2, we can observe the following:

- if $\Delta \mathrm{P}>0$ and $\Delta \mathrm{V}>0$, so $(\Delta \mathrm{P} / \Delta \mathrm{V})>0$, then the duty cycle $(D)$ was decreased by $(-\Delta D)$,

- if $\Delta \mathrm{P}>0$ and $\Delta \mathrm{V}<0$, so $(\Delta \mathrm{P} / \Delta \mathrm{V})<0$, then the duty cycle $(D)$ was increased by $(+\Delta D)$,

- if $\Delta \mathrm{P}<0$ and $\Delta \mathrm{V}>0$, so $(\Delta \mathrm{P} / \Delta \mathrm{V})<0$, then the duty cycle $(D)$ was decreased by $(+\Delta D)$,

- if $\Delta \mathrm{P}<0$ and $\Delta \mathrm{V}<0$, so $(\Delta \mathrm{P} / \Delta \mathrm{V})>0$, then the duty cycle $(D)$ was increased by $(-\Delta D)$,

- if $\Delta \mathrm{P}=0$, then the MPP is achieved.

Taking $E=(\Delta \mathrm{P} / \Delta \mathrm{V})$, for each step and by considering the sign of $\Delta \mathrm{P}$ and $\Delta \mathrm{V}$, we conclude that:

$$
\begin{aligned}
& \text { If } E<0 \text {, then } D=D+\Delta D, \\
& \text { If } E>0 \text {, then } D=D-\Delta D, \\
& \text { If } E=0 \text {, then } D=D .
\end{aligned}
$$

Motivated by this discussion, the error $E$ has been defined as an input to the fuzzy logic controller, and the change of the duty ratio $d D$ as an output for it. The FLC's output $d D$ is multiplied by a discrete time integrator with Forward Euler 
method (the default) to obtain the duty cycle $(D)$ in (4); where the gain value $K$ and the sample time $T$ of the integrator are set to 1 and 0.01 respectively

$$
D(k)=D(k-1)+k \cdot T \cdot d D(k-1) \text {. }
$$

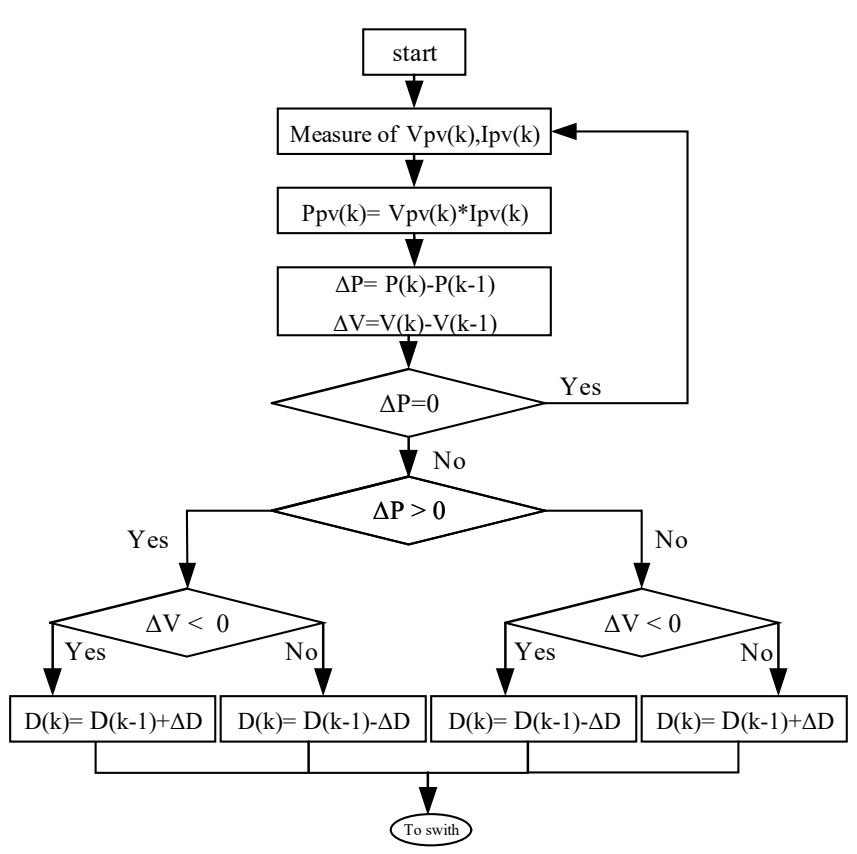

Fig. 2. Flow chart of conventional P\&O algorithm.

Depending on the value (positive or negative) of the fuzzy controller output $d D$, the block uses the following steps to compute its output $D$ :

$$
\begin{aligned}
& \text { step } 0: D(0)=\text { consant, } \\
& \text { step } 1: D(1)=D(0)+T \times d D(0), \\
& \text { step } 2: D(2)=D(1)+T \times d D(1), \\
& \text {..... } \\
& \text { step } n: D(n)=D(n-1)+T \times d D(n-1) .
\end{aligned}
$$

The input and output of the FLC have three language variables: negative $(\boldsymbol{N})$, positive $(\boldsymbol{P})$, and zero $(\boldsymbol{Z O})$; its membership functions are shown in Fig. 3, where $\phi$ and $K$ are used to expand or shrink the membership functions along the universe of discourse, and $r \in[0,1]$ is used to adjust the center point of the input. In this paper $K, \phi$, and $r$ are set to $1,4.96$, and 0.33 respectively.

The linguistic expressions used for the fuzzy control rules are given as follows:

$$
\begin{gathered}
R_{1}: \text { If } E \text { is } N \text {, then } d D \text { is } P, \\
R_{2}: \text { If } E \text { is } Z O, \text { then } d D \text { is } Z O, \\
R_{3}: \text { If } E \text { is } P, \text { then } d D \text { is } N,
\end{gathered}
$$

where $E$ is $\boldsymbol{N}$ signifies that the location of the operating point is in the right half plan; then a positive change $\boldsymbol{P}$ of $d D$ is required to reach the MPP. The two remaining fuzzy rules for the proposed TS-FLC are based on the same concept. The final step after the determination of membership functions and fuzzy rules is the defuzzification, which is the procedure of determining a crisp control for fuzzy. Many defuzzification methods are reported in the literature: the mean of maximum, the maximum criterion, the center of area, and the weighted average method as reported in [24]. In our work, we have used the weighted average method to get the crisp control for fuzzy.

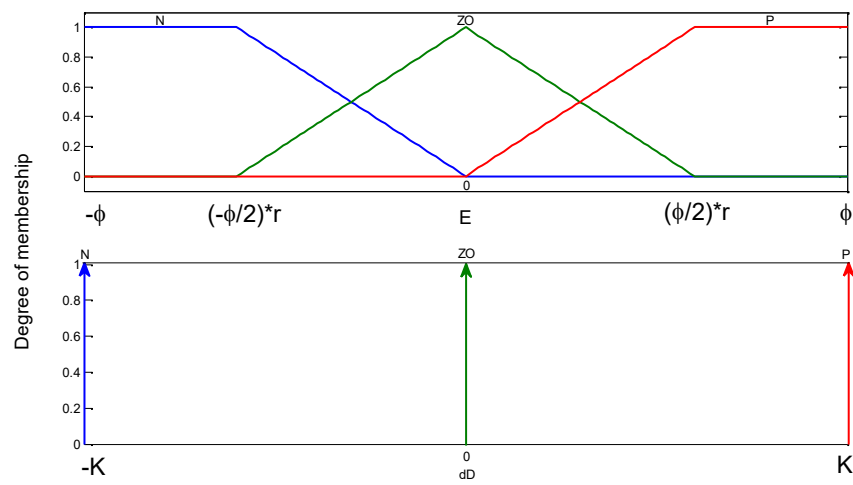

Fig. 3. Input $(E)$ and output $(d D)$ membership functions for proposed FLC

$$
d D=\frac{\sum_{i=1}^{3} C_{f i} \mu_{i}(E)}{\sum_{i=1}^{3} \mu_{i}(E)},
$$

where $C_{f}$ is the associated singleton membership function of $d D . \mu_{i}(E)$ : Degree of membership of the variable E.

\section{B. Proposed Algorithm under Partial Shading Conditions}

Due to its nonlinearity, robustness, natural adaptivity, and a wide range of search, the proposed SIFLC can track the global MPP. The preset values of the panel power and voltage are used in each instance to calculate the FLC input (E) based on the following cases:

- if $E$ is positive big, where the operating point is on the left half plan and far from the MPP, then the duty cycle is decreased,

- if $E$ is positive mid (between zero and positive big), then the duty cycle is mid and will decrease to achieve the MPP,

- if $E$ is negative big/mid, where the operating point is on the right half plan far/near from the MPP, then the duty cycle is large/mid and will increase to achieve the MPP,

- if $E$ is zero and the duty cycle is zero, then the MPP is reached.

Therefore, during varying climatic conditions or partial shading, the initial value of duty cycle shall be well given to make a wide range of power scan and store the maximum available PV power. On the other hand, when the operating point reaches the global MPP, the duty cycle decreases to minimize any oscillation around the global MPP. Based on the previous discussion, the proposed FLC is an MPPT controller with variable step size $(\Delta \mathrm{D})$. By contrast, the conventional $\mathrm{P} \& \mathrm{O}$ algorithm cannot precisely track the global MPP because it uses a fixed step size $(\Delta D)$ to perturb the duty cycle.

\section{RESULTS AND DISCUSSION}

\section{A. Simulation Results}

The simulation of the functional diagram (Fig. 1) has been conducted via MATLAB-SIMULINK platform using 
parameters reported in Appendix A (Table A-I and Table AII). Optimization of the SI-TS-FLC has been carried out under standard climatic conditions: $\mathrm{T}=25{ }^{\circ} \mathrm{C}$ and $S=1000$ $W / m^{2}$. Fig. 4 shows the cost function evolution during the optimization process using PSO; after 20 iterations, the PSO algorithm converges to the optimal parameters presented in Table I. The simulation results of the PV system by applying the optimized SI-TS-FLC controller are shown in Fig. 5. The system tracks the MPP within a short settling time and with less oscillation around it.

TABLE I. OPTIMAL PARAMETERS OF THE SI-TS-FLC.

\begin{tabular}{|c|c|c|}
\hline $\boldsymbol{\phi}$ & $\mathbf{r}$ & $\mathbf{K}$ \\
\hline 4.967 & 0.3309 & 1 \\
\hline
\end{tabular}

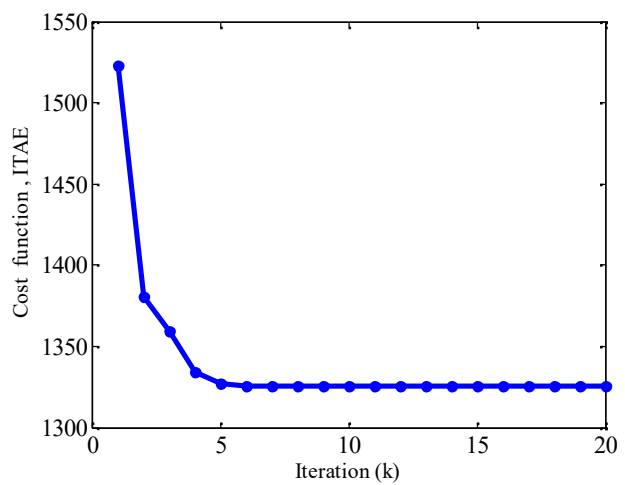

Fig. 4. Evolution of the cost function ITAE vs iteration.

To extend the applicability of the proposed SI-TS-FLC controller under variable climatic conditions, a robustness test has been carried out under various inputs of temperature and irradiance (Fig. 6). Same parameters presented in Table I have been used. In addition, performance of the proposed controller has been compared with those obtained by the conventional $\mathrm{P} \& \mathrm{O}$ algorithm. The simulation results are presented in Fig. 7.

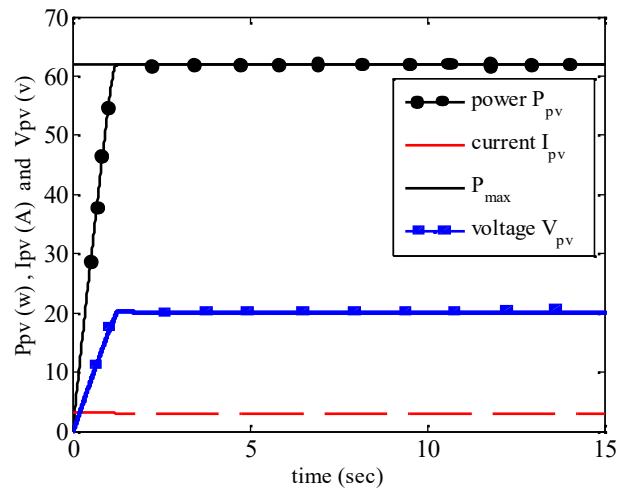

(a)

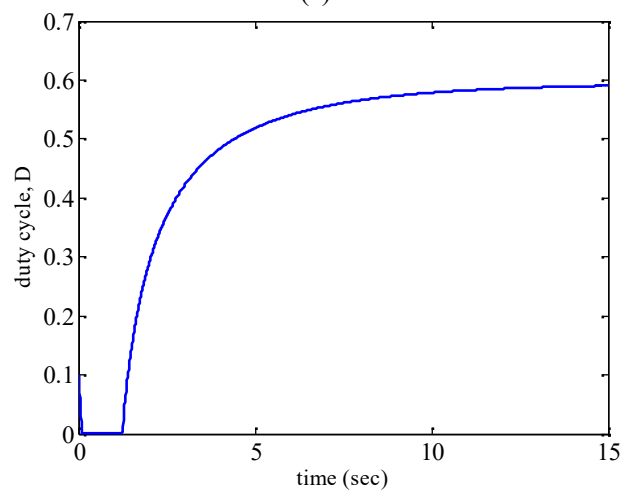

(b)

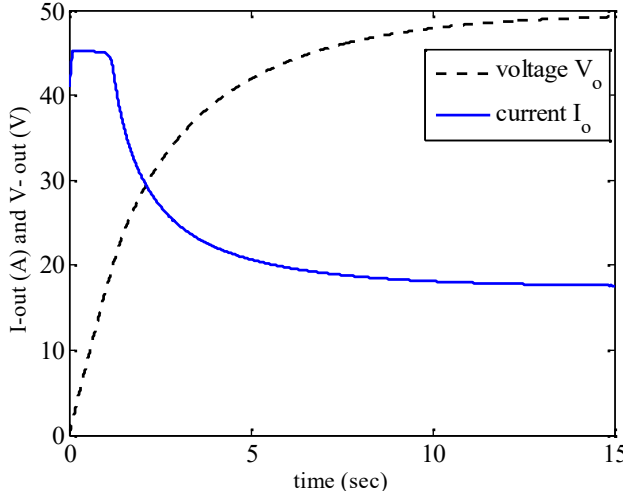

(c)

Fig. 5. Simulation results of the controlled PV: a) PVG power, current and voltage; b) duty cycle; c) output current and voltage.

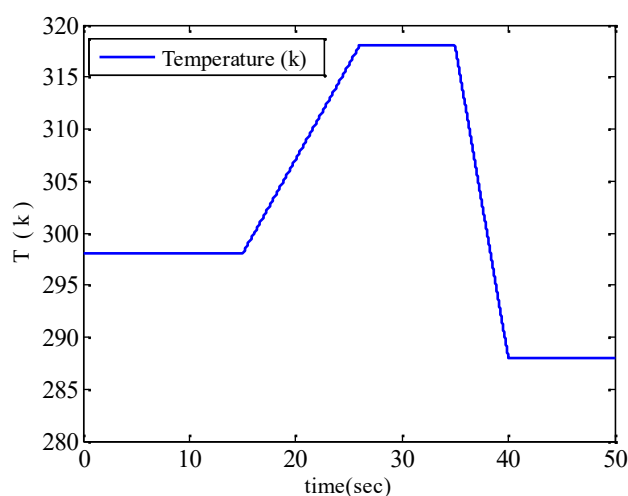

(a)

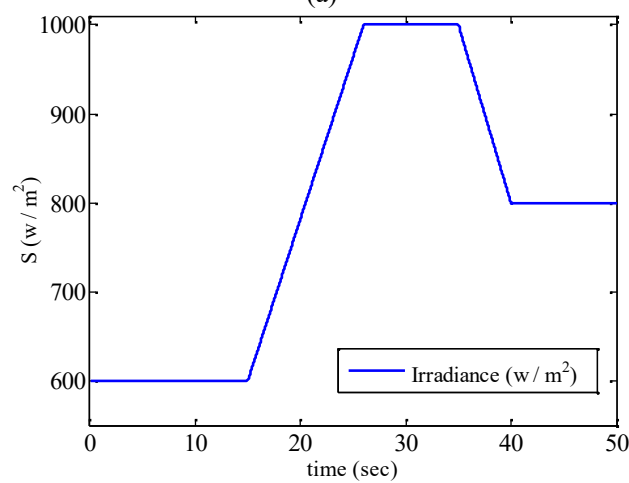

(b)

Fig. 6. Temperature (a) and Irradiance (b) profile.

As shown in Fig. 6(a), at $t=15 \mathrm{~s}$ to $\mathrm{t}=25 \mathrm{~s}$, both temperature and irradiation increase. The proposed controller with the same FLC parameters obtained under standard climatic condition can quickly track the new MPP under variable climatic conditions as depicted in Fig. 7(a) and Fig. 7(b).

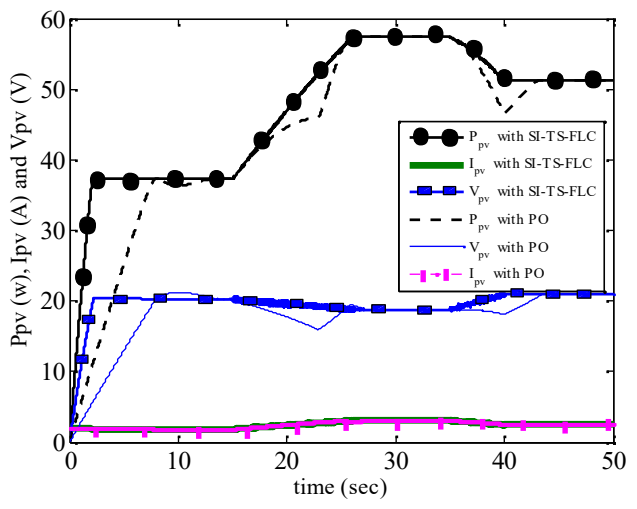

(a) 


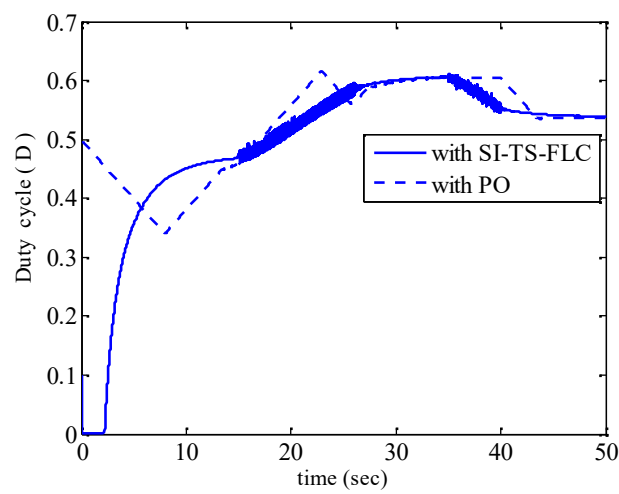

(b)

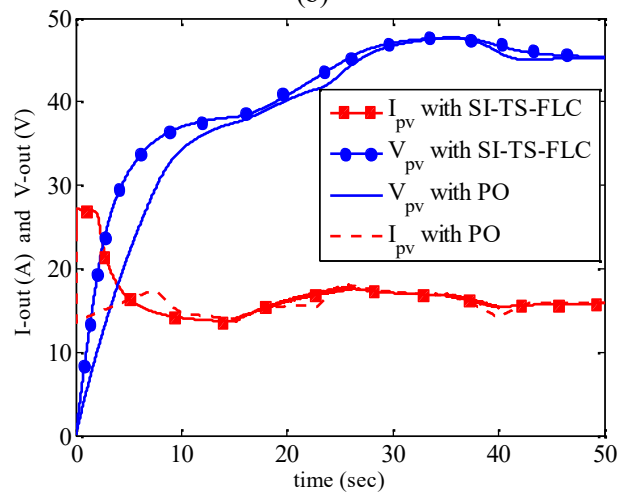

(c)

Fig. 7. Simulation results of the controlled PV system under variable climatic condition using optimized SI-TS-FLC by PSO (solid line), and P\&O algorithm (dashed line): a) PV power, current and voltage; b) duty cycle; c) output current and voltage.

Furthermore, the proposed controller performs just as well under the standard condition in terms of less settling time in transient state and without oscillation on the steady-state regime compared with the conventional $\mathrm{P} \& \mathrm{O}$ algorithm as seen in power and current voltage duty cycle waveforms.

Figure 7(c) shows the output power, current, and voltage waveforms of PVG system.

\section{B. Experimental Results}

Both algorithms, the proposed SI-TS-FLC and conventional P\&O, are implemented in real-time for MPPT control using a DSPACE1104 card with TMQ320F240 DSP $(20 \mathrm{MHz})$ and a microprocessor PC 603e (250 MHZ). The DSPACE1104 card is connected to the converter via two interface cards that receive and emit signal control. The current and voltage have been measured using acquisition cards which are equipped with two sensors, namely, LA25AP and LV25P, for current and voltage, respectively. The test bench as shown in Fig. 8 consists mainly of an
Agilent modular solar array simulator to generate $\mathrm{I}-\mathrm{V}$ curves using parameters in Appendix A, a DC-DC converter with $20 \mathrm{kHz}$ switching frequency, and a resistive load connected to the DC-DC converter. The different parameters of the experimental setup are described in Appendix A. The experimental study has been conducted under various scenario which is different from those considered in the simulation. The newly considered conditions is: the system runs under partial shading condition. Results are discussed in the following subsections.

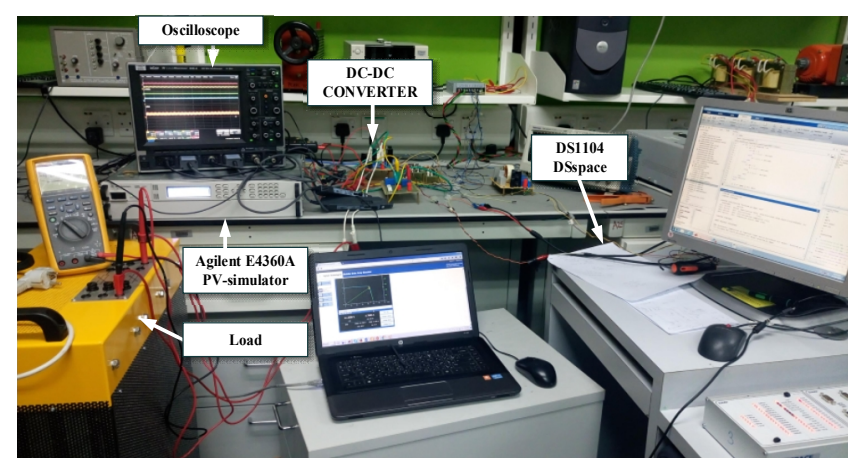

Fig. 8. Experiment set-up of the MPPT PV system.

\section{1) Experimentation under Partial Shading Condition}

In real-world application, sometimes the irradiance is unequally distributed on the top of the PV module and this is what we call the partial shading phenomena. In this case, multiple locals and global maxima appear in the $\mathrm{I}-\mathrm{V}$ and $\mathrm{P}-$ $\mathrm{V}$ curves, as shown in Fig. 9(b). Therefore, the conventional control techniques like Hill clumping (HC) and/or P\&O method cannot track the global maxima [10]. Recently, to track the global maxima, several researchers used artificial intelligent techniques such as PSO [10], [11], FE [12], and FLC [16], [23]. In this paper, we have developed and optimized our SI-TS-FLC algorithm under partial shading condition to track the GMPP. The data shown in Fig. 9(a) and Fig. 9(b) have been obtained by programming the Agilent EA4360 modular solar array simulator available in Power Electronics and Renewable Energy Research Laboratory (PEARL). The results are as follows:

Figure 10(a) and Fig. 10(b) show the tracked power output of the PV system under partial shading condition using conventional P\&O and the herein proposed SI-TSFLC tracking algorithm, respectively. The PV system first operates under clear sky condition as shown in Fig. 9(a) and with a peak power of $117 \mathrm{w}$. Partial shading occurs at $\mathrm{t}=$ $10.5 \mathrm{~s}$, as shown in Fig. 9(b).

TABLE II. COMPARISON THE PREVIOUS WORKS WITH PROPOSED TECHNIQUE.

\begin{tabular}{|c|c|c|c|c|c|}
\hline $\begin{array}{c}\text { Work, publication } \\
\text { year }\end{array}$ & MPPT technique & $\begin{array}{c}\text { Tracking } \\
\text { efficiency \%o }\end{array}$ & $\begin{array}{c}\text { Tracking } \\
\text { speed }\end{array}$ & $\begin{array}{c}\text { Accuracy- } \\
\text { power } \\
\text { oscillations }\end{array}$ & $\begin{array}{c}\text { Switching } \\
\text { frequency }\end{array}$ \\
\hline$[17] 2015$ & Fuzzy logic controller (2 inputs-49 rules) & 96 & $0.125 \mathrm{~s}$ & $1.2 \%$ & $15 \mathrm{kHz}$ \\
\hline$[13] 2016$ & Modified Firefly Algorithm & 99.4 & $1.87 \mathrm{~s}$ & $2.5 \%$ & $100 \mathrm{kHz}$ \\
\hline$[25] 2013$ & Modified fuzzy-logic controller (2inputs-5 rules) & 97 & $0.01 \mathrm{~s}$ & $3.7 \%$ & $4 \mathrm{kHz}$ \\
\hline$[12] 2016$ & Fireworks Enriched P\&O Algorithm & 98 & $1.1 \mathrm{~s}$ & $0.5 \%$ & $20 \mathrm{kHz}$ \\
\hline$[29]$ 2014 & Adaptive P\&O-Fuzzy MPPT.inc.cond & 95.2 & $0.02 \mathrm{~s}$ & $0.5 \%$ & - \\
\hline Proposed technique & SI-TS-FLC Algorithm (1 input-3 rules) & 98.5 & $0.43 \mathrm{~s}$ & $1.7 \%$ & $20 \mathrm{kHz}$ \\
\hline
\end{tabular}




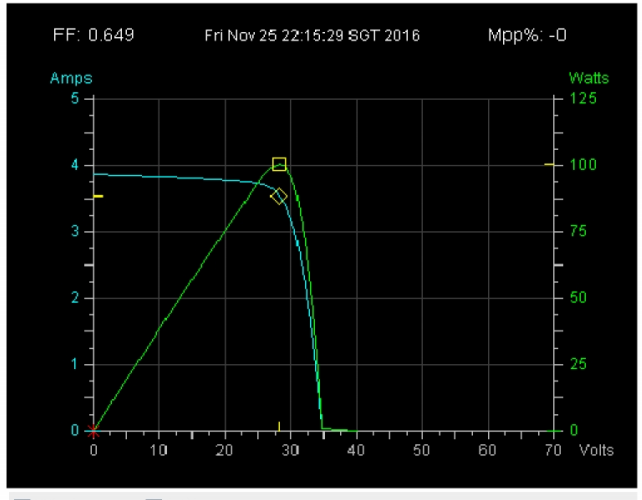

(a)

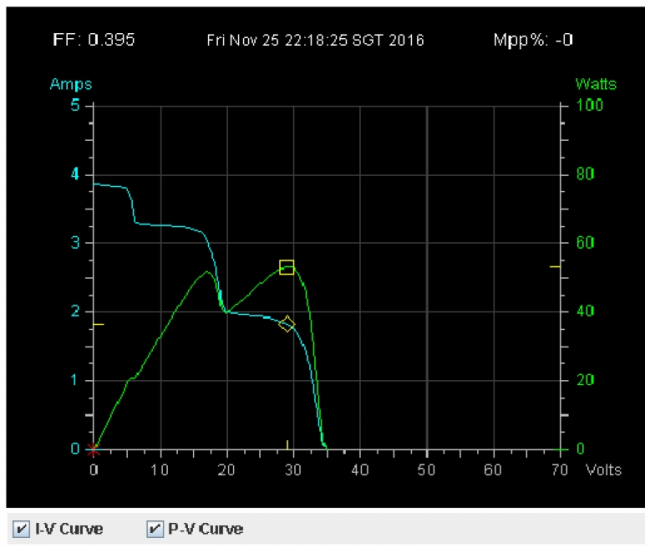

(b)

Fig. 9. PV characteristics with normal and partial shading conditions (a), and (b) respectively.

Consequently, the P-V curve is characterized by two peaks: one for the Global MPP with $53 \mathrm{w}$ and the second for Local MPP with $44 \mathrm{w}$. In the case of conventional P\&O Fig. 10(a), the algorithm tracks a local peak of $41 \mathrm{w}$, which is considered as a GMPP by the algorithm.

The settling time was found equal to $\sim 28.2 \mathrm{~ms}$. Although P\&O offers a short settling time, the difference between the MPP found by the algorithm and the GMPP is almost $12 \mathrm{w}$. This difference of $12 \mathrm{w}$ presents a significant loss for the PV system.

In Fig. 10(b) where our controller of SI-TS-FLC has been implemented, when the partial shading is imposed on the PV system, the algorithm updates the new MPP taking $432.2 \mathrm{~ms}$ of settling time which is, in fact, longer than conventional $\mathrm{P} \& \mathrm{O}$, however our algorithm successfully tracked down the true global MPP with tracking efficiency of $\sim 98.5 \%$.

Based on the results presented above, one can say that the proposed controller performs better compared to conventional $\mathrm{P} \& \mathrm{O}$ in terms of dynamic performance due to partial shading condition. To demonstrate the effectiveness of the proposed controller against the most recent published works [12], [13], [17], [25], [29], a comparative study has been made under partial shading condition. The proposed SI-TS-FLC has been implemented via DS1104 Dspace and the key results for the comparative study are presented in Table II. The dynamic performance of the present algorithm is similar to those obtained by [12], [13]. However, tracking speed is longer than the proposed algorithm. In addition, in terms of tracking efficiency, the present algorithm offers
$98.5 \%$ of efficiency and performs better than methods proposed in [17], [25], [29]. Moreover, low steady-state oscillation (around $1.7 \%$ ) is also one of the key advantages of the proposed SI-TS-FLC control algorithm.
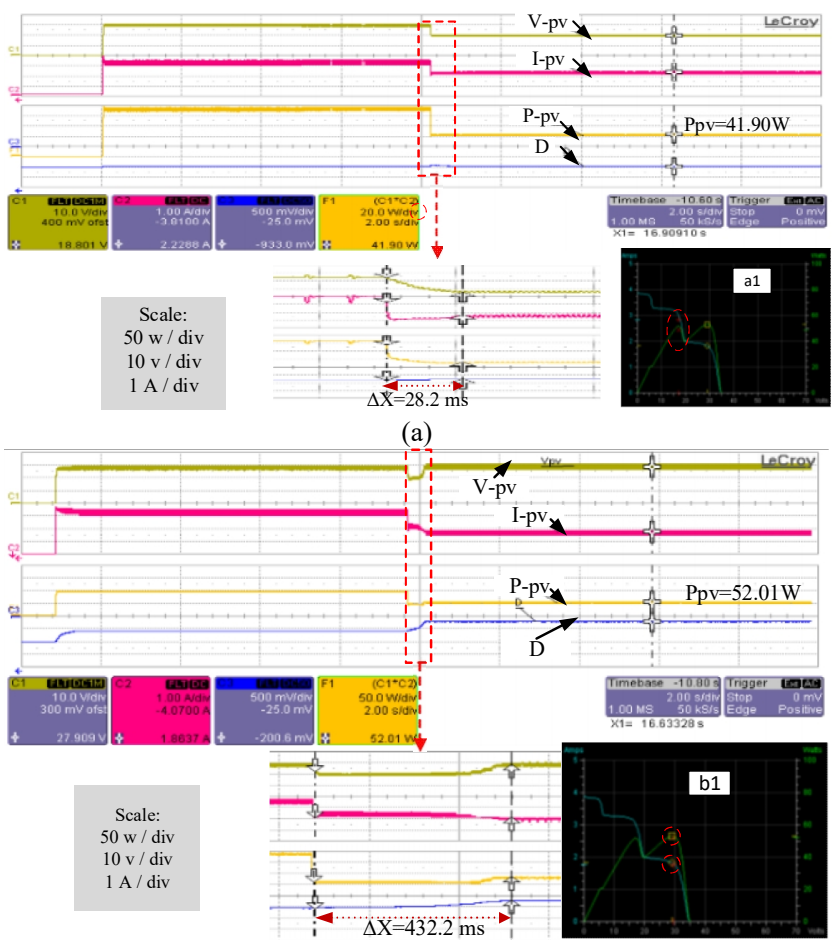

(b)

Fig. 10. Experimental tracking performance under partial shading conditions: a) P\&O method; b) proposed method.

\section{CONCLUSIONS}

An intelligent control technique of a single input T-S FLC is proposed for the MPP tracking of a PV system with DCDC converter and resistive load. To the best of our knowledge, this study is the first to propose the use of single input in the fuzzy controller. The number of fuzzy rules and linguistic variables is reduced to three. For the reason of simplification, the MPPT synthesis and decreasing the calculation time. Also to be easy to implemented in real time.

The proposed controller has been tested under variable temperature, irradiance, and partial shading condition. Simulation and experimental results have been carried out to evaluate the effectiveness of the proposed controller system. Based on the results, the proposed approach is effective in tracking the MPP under different conditions compared with the commonly used P\&O algorithm in terms of less settling time at the transient state and minimum oscillation in the steady-state regime. Furthermore, the proposed controller has effectively handled the common phenomena in a PV system, namely, partial shading condition, and tracked perfectly the global maxima.

The present study proposes an approach to the efficient use of MPPT control in solar system technologies. The proposed control approach, if integrated into the solar system, will be a reliable solution to increase the efficiency of these systems and enable them to participate in the electrification of remote off-grid regions. 


\section{APPENDIX A}

TABLE A-I. PVG SIMULINK MODEL PARAMETERS.

\begin{tabular}{|c|c|}
\hline Equivalent resistance in series :Rs $(\Omega)$ & $15 \mathrm{~m} \Omega$ \\
\hline Equivalent resistance in parallel: $\operatorname{Rp}(\Omega)$ & $30 \Omega$ \\
\hline Number of cells connected in series: $\mathrm{Ns}$ & 36 \\
\hline Number of cells connected in parallel: $\mathrm{Np}$ & 1 \\
\hline Ideality factor of diode d1:n1 & 1 \\
\hline Ideality factor of diode d2:n2 & 2 \\
\hline
\end{tabular}

Note: DC-DC converter parameters: $L=3.5 \mathrm{mH}, C_{1}=C_{2}=5.6 \mathrm{mF}$; PSO algorithm parameters: $c_{1}=c_{2}=2.05$

TABLE A-II. PVG EMULATOR PARAMETERS.

\begin{tabular}{|c|c|}
\hline Short circuit current(A) & 3 \\
\hline Current at MPP(A) & 2.57 \\
\hline Open circuit voltage(V) & 50 \\
\hline Voltage at MPP(V) & 45.075 \\
\hline Power of MPP & 117.7 \\
\hline
\end{tabular}

\section{ACKNOWLEDGMENTS}

The Authors greatly acknowledge the Algerian Ministry of Higher Education and Scientific Research. They also thank the Power Electronics and Renewable Energy Research Laboratory (PEARL) at Malaya University for granting access to necessary research facilities.

\section{REFERENCES}

[1] Renewables. Global Status Report. (2016). REN21 (Renewable energy policy network for the 21 st century). [Online]. Available: http://www.ren21.net/status-of-renewables/global-status-report/

[2] N. Femia, G. Petrone, G. Spagnuolo, M. Vitelli, "Optimization of perturb and observe maximum power point tracking method", IEEE Trans Power Electron. vol. 20, no. 4, pp. 963-973, 2005. DOI: 10.1109/TPEL.2005.850975.

[3] J. Ahmed, Z. Salam, "An improved perturb and observe (P\&O) maximum power point tracking (MPPT) algorithm for higher efficiency", Appl Energy, vol. 150, no. 1, pp. 97-108, 2015. DOI: 10.1016/j.apenergy.2015.04.006.

[4] C. Duy Huynh, W. Matthew Dunnigan, "Development and comparison of an improved incremental conductance algorithm for tracking the MPP of a solar PV panel", IEEE Trans. Sustainable Energy, vol. 7, no. 4, pp. 1421-29, 2016. DOI: 10.1109/TSTE.2016.2556678.

[5] K. Tey, S. Mekhilef, "Modified incremental conductance algorithm for photovoltaic system under partial shading conditions and load variation", IEEE Trans. Ind Electron., vol. 61, no. 10, pp. 53845392, 2014. DOI: 10.1109/TIE.2014.2304921.

[6] I. Houssamo, F. Locment, M. Sechilariu, "Maximum power tracking for photovoltaic power system: Development and experimental comparison of two algorithms", Renew. Energy, vol. 35, no. 10, pp. 2381-2387, 2010. DOI: 10.1016/j.renene.2010.04.006.

[7] E. Bianconi, J. Calvente, R. Giral, "Perturb and observe MPPT algorithm with a current controller based on the sliding mode", Int $J$ Electr Power Energy Syst, vol. 44, no. 1, pp. 346-356, 2013. DOI: 10.1016/j.ijepes.2012.07.046.

[8] W. Lin, C. Hong, C. Chen, "Neural-network-based MPPT control of a stand-alone hybrid power generation system", IEEE Trans. Power Electron, vol. 26, no. 12, pp. 3571-3581, 2011. DOI: 10.1109/TPEL.2011.2161775.

[9] Syafaruddin, E. Karatepe, T. Hiyama, "Artificial neural networkpolar coordinated fuzzy controller based maximum power point tracking control under partially shaded conditions", IET Renew Power Gener, vol. 3, no. 2, pp. 239-253, 2009. DOI: 10.1049/ietrpg:20080065.

[10] K. Ishaque, Z. Salam, "A deterministic particle swarm optimization maximum power point tracker for photovoltaic system under partial shading condition", IEEE Trans. Ind Electron, vol. 60, no. 8, pp. 3195-3206, 2012. DOI: 10.1109/TIE.2012.2200223.

[11] Y. Zhao, X. Zhao, Y. Zhang, "MPPT for photovoltaic system using multi-objective improved particle swarm optimization algorithm", TELKOMNIKA Indones J Electr Eng, vol. 12, no. 1, pp. 261-268, 2014. DOI: 10.11591/telkomnika.v12i1.39.
[12] C. Manickam, G. Raman, S. Ganesan, N. Chilakapati, "Fireworks enriched $\mathrm{P} \& \mathrm{O}$ algorithm for GMPPT and detection of partial shading in PV systems", IEEE Trans. Power Electron, vol. 32, no. 6, pp. 4432-4443, 2016. DOI: 10.1109/TPEL.2016.2604279.

[13] D. Teshome, C. Lee, Y. Lin, K. Lian, "A modified firefly algorithm for photovoltaic maximum power point tracking control under partial shading", IEEE J Emerg Sel Top Power Electron, vol. 5, no. 2, pp. 661-671, 2016. DOI: 10.1109/JESTPE.2016.2581858.

[14] A. Dounis, P. Kofinas, G Papadakis, C. Alafodimos, "A direct adaptive neural control for maximum power point tracking of photovoltaic system", Sol Energy, vol. 115, pp. 145-165, 2015. DOI: 10.1016/j.solener.2015.02.004

[15] T. Mitja, H. Alenka, M. Miro, R. Miran, "Adaptive fuzzy-logic state controller for DC-DC step-down converter", Electrical Engineering journal, pp. 1-13, 2017. DOI: 10.1007/s00202-017-0545-z.

[16] R. Guruambeth, R. Ramabadran, "Fuzzy logic controller for partial shaded photovoltaic array fed modular multilevel converter", IET Power Electron, vol. 9, no. 8, pp. 1694-1702, 2016. DOI: 10.1049/iet-pel.2015.0737

[17] A. Menadi, S. Abdeddaim, A. Betka, M. Benchouia, "Real time implementation of a fuzzy logic based MPPT controller for grid connected photovoltaic system", Int J Renew Energy Res, vol. 5, no. 1, 2015. [Online]. Available. http://www.ijrer.org/ijrer/index.php/ ijrer/article/viewFile/1952/pdf 33

[18] B. Alajmi, K. Ahmed, S. Finney, B. Williams, "Fuzzy-logic-control approach of a modified hill-climbing method for maximum power point in microgrid standalone photovoltaic system", IEEE Trans. Power Electron, vol. 26, no. 4, pp. 1022-1030, 2011. DOI: 10.1109/TPEL.2010.2090903.

[19] S. Tang, Y. Sun, Y. Chen, Y. Zhao, Y. Yang, W. Szeto, "An enhanced MPPT method combining fractional-order and fuzzy logic control", IEEE J Photovoltaics, vol. 7, no. 2, pp. 640-650, 2017. DOI: 10.1109/JPHOTOV.2017.2649600.

[20] A. Nabulsi, R. Dhaouadi, H. Rehman, "Single input fuzzy controller (SFLC) based maximum power point tracking", in IEEE Fourth Int. Conf. Modeling, Simulation and Applied Optimization, 2011, pp. 15. DOI: 10.1109/ICMSAO.2011.5775508.

[21] B. Noureddine, B. Djamel, F. Boudjema, "A hybrid fuzzy fractional order PID sliding-mode controller design using PSO algorithm for interconnected nonlinear systems", CEAI, vol. 17, no. 1, pp. 41-51, 2015. DOI: $10.1109 /$ ICoSC.2013.6750949.

[22] B. Alajmi, K. Ahmed, S. Finney, B. Williams, B. Wayne, "A maximum power point tracking technique for partially shaded photovoltaic systems in microgrids", IEEE Trans. Ind Electron, vol. 60, no. 4, pp. 1596-1606, 2011. DOI: 10.1109/TIE.2011.2168796.

[23] A. Messai, A. Mellit, A. Guessoum, S. Kalogirou, "Maximum power point tracking using a GA optimized fuzzy logic controller and its FPGA implementation", Sol Energy, vol. 85, no. 2, pp. 265-277, 2011. DOI: 10.1016/j.solener.2010.12.004.

[24] P. Cheng, B. Peng, Y. Liu, Y. Cheng, J. Huang, "Optimization of a fuzzy-logic-control-based MPPT algorithm using the particle swarm optimization technique", Energies, vol. 8, no. 6, pp. 5338-5360, 2015. DOI: $10.3390 / \mathrm{en} 8065338$.

[25] R. Rahmani, M. Seyedmahmoudian, S. Mekhilef, R. Yusof, "Implementation of fuzzy logic maximum power point tracking controller for photovoltaic system", Am J Appl Sci, vol. 10, no. 3, pp. 209-218, 2013. DOI: 10.3844/ajassp.2013.209.218.

[26] N. Bouarroudj, D. Boukhetala, A. Djari, Y. Rais, B. Benlahbib, "FLC based gaussian membership functions tuned by PSO and GA for MPPT of photovoltaic system: a comparative study", in Proc. 6th Int Conf Syst Control (ICSC 2017), 2017, pp. 317-322. DOI: 10.1109/ICoSC.2017.7958640.

[27] B. Benlahbib, F. Bouchafaa, S. Mekhilef, N. Bouarroudj, "Wind farm management using artificial intelligent techniques", Int $J$ Electr Comput Eng, vol. 7, no. 3, pp. 1133-1144, 2017. DOI: 10.11591/ijece.v7i3.pp1133-1144.

[28] B. Benlahbib, N. Bouarroudj, F. Bouchafaa, B. Batoun, "Fractional order PI controller for wind farm supervision", in Proc. IEEE Int Conf IndEng Eng Manag, 2014, pp. 1234-1238. DOI: 10.1109/IEEM.2014.7058835.

[29] N. Rahim, A. Che Soh, R. Mam, Z. Maam, "Development of adaptiveperturb and observe-fuzzy control maximum power point tracking for photovoltaic boost dc-dc converter", IET Renew Power Gener, vol. 8, no. 2, pp. 183-194, 2014. DOI: 10.1049/ietrpg.2012.0362. 